Redesigning the ICU Nursing Discharge Process; A Quality Improvement Study

Short Title: Redesigning the ICU Discharge Process

Wendy Chaboyer PhD, RN

Director, Research Centre for Clinical and Community Practice Innovation

Griffith University,

Griffith University, Queensland, Australia, 4222

W.Chaboyer@griffith.edu.au

Telephone: 61766528518

Fax: 61755518526

Frances Lin

Research Centre for Clinical and Community Practice Innovation, Griffith University, Phone: 61755528595

Fax: 61755528526

Address: Griffith University Gold Coast campus

Griffith University, Qld, 4222, Australia

F.Lin@griffith.edu.au

Michelle Foster

Nurse Unit Manager ICU, Gold Coast Hospital,

Phone: 61755198279

109 Nerang Street, Southport, Qld, 4215, Australia

Michelle_Foster@health.qld.gov.au

Lorraine Retallick

ICU Liaison Nurse, Gold Coast Hospital,

Phone: 61755198571

Lorraine_Retallick@health.qld.gov.au

109 Nerang Street, Southport, Qld, 4215, Australia

Kriengsak Panuwatwanich, $\mathrm{PhD}$

Research Fellow, Centre for Infrastructure Engineering and Management, Griffith

School of Engineering, Griffith University, Gold Coast, Queensland, Australia

Phone: 6175527357

Address: Griffith University Gold Coast campus

Griffith University, Qld, 4222, Australia

K.Panuwatwanich@griffith.edu.au

Brent Richards

Medical Director, ICU Gold Coast Hospital,

Phone: 61755198279

109 Nerang Street, Southport, Qld, 4215, Australia

Brent_Richards@health.qld.gov.au

Address correspondence to Wendy Chaboyer 


\begin{abstract}
Purpose: To evaluate the impact of a redesigned intensive care unit (ICU) nursing discharge process on ICU discharge delay, hospital mortality and ICU readmission within 72 hours.
\end{abstract}

Methods: A quality improvement study using a time series design and statistical process control analysis was conducted in one Australian general ICU. The primary outcome measure was hours of discharge delay per patient discharged alive per month, measured for 15 months prior to, and for 12 months after the redesigned process was implemented. The redesign process included appointing a change agent to facilitate process improvement, developing a patient handover sheet, requesting ward staff to nominate an estimated transfer time and designing a daily ICU discharge alert sheet that included an expected date of discharge.

Results: A total of 1,787 ICU discharges were included in this study, 1,001 in the 15 months before and 786 in the 12 months after the implementation of the new discharge processes. There was no difference in in-hospital mortality after discharge from ICU or ICU readmission within 72 hours during the study period. However, process improvement was demonstrated by a reduction in the average patient discharge delay time of 3.2 hours (from 4.6 hour baseline to 1.0 hours postintervention).

Conclusions: Involving both ward and ICU staff in the redesign process may have contributed to a shared situational awareness of the problems, which led to more timely and effective ICU discharge processes. The use of a change agent, whose ongoing role involved follow-up of patients discharged from ICU, may have helped to embed the new process into practice. 
Keywords: Intensive Care, Patient Discharge, Nursing, Quality Improvement, Time Series, Statistical Process Control 


\section{Redesigning the ICU Nursing Discharge Process; A Quality Improvement Study}

The Intensive Care Unit (ICU) discharge process is complex, involving information exchange among ICU and ward staff in addition to transferring responsibility and accountability for care (Australian Medical Association 2006). Despite professional guidelines for managing ICU discharge processes (Intensive Care Society 1997; Society of Critical Care Medicine 1999), there are wide variations in practice (Heidegger et al. 2005). Discharges can be problematic, with issues such as bed-block (Levin \& Sprung 2001; Levin et al. 2003; Chaboyer et al. 2006; McLaughlin et al. 2007), inadequate skill mix on the receiving wards (Whittaker \& Ball 2000; Levin et al. 2003) and resource limitations creating delays (Levin et al. 2003). Outflow limitations were identified in one in six ICU patient discharges (Levin et al. 2003). Perrens et al. (2008) found that $28 \%$ of medical ICU transfer reports contained at least one critical or serious error, with 8 or more discharge medications being predictive of such errors. The risk of errors has also been found to be associated with discharge time, particularly night (Goldfrad \& Rowan 2000; Beck et al. 2002; Duke et al. 2005; Priestap \& Martin 2006) and weekend (Bell \& Sales 2004; Laupland 2008) discharges. One analysis of patients discharged from 26 ICUs in the UK between 1995-98 showed that patients discharged at night were about 2.5 times as likely to die while in hospital (Goldfrad \& Rowan 2000).

A number of approaches have been trialled to improve the discharge process. Gajic et al. (2008) developed an ICU readmission prediction score to better determine patients ready for discharge. Others have focused on quantifying the residual amount of organ dysfunction/failure and associated workload (Moreno \& Agthé 1999; Smith et al. 1999; Moreno et al. 2001) in order to decrease post-ICU discharge mortality. Handover communication (Whittaker \& Ball 2000) has attracted considerable 
research focus, including associated discharge documentation (Hall-Smith et al. 1997), and nurse monitoring of medical transfer notes (Perrens et al. 2008). ICU liaison or outreach services and process mapping have also been used to improve the ICU discharge process, with one study finding that use of an ICU liaison nurse can significantly reduce discharge delay (Chaboyer et al. 2006). Crocker and Keller (2005) used process mapping to remove several unnecessary steps in the discharge process, which actually improved communication. More recently, Shahani and colleagues (2008) demonstrated how, using a simulation model and real data from a number of hospitals, critical care admissions could be predicted, which plausibly might help to better plan discharges as well. Building on this previous work, the aim of the current study was to evaluate the impact of an ICU nursing discharge process redesign. Quality improvement indicators included ICU discharge delay, mortality after ICU discharge and ICU readmission within 72 hours.

\section{Methods}

This quality improvement study used a time series design (Speroff \& O’Conner 2004) and statistical process control analysis (SPC) (Benneyan et al. 2003). We hypothesised that a new nursing ICU discharge process would decrease delay time per patient. Secondary outcomes we believed would show no difference included mortality after ICU discharge and ICU readmission within 72 hours.

\section{$\underline{\text { Setting }}$}

The study setting was a 12 bed general ICU in a 580 bed metropolitan hospital in Queensland, Australia. The hospital does not have a high dependency unit (HDU), however beds in the ICU can be designated as HD. The ICU admits about 1,000 medical and surgical patients per year, with an average patient length of stay (LOS) of 3.2 days. Approximately $60 \%$ of patients admitted are non-operative and $40 \%$ 
operative. No cardiac surgery is performed at the site and burns patients are stabilized then transferred to another hospital. This study was approved by the hospital's and university's human research ethics committees. Medical and nursing participants were given an information summary and provided written consent. Because data were collected from staff, patient consent was waived, with only patient assent to the researchers collecting data at their bedside being required by the ethics committees.

\section{$\underline{\text { Baseline Discharge Processes }}$}

Data comprised observational, interview and documents analysis. To create a baseline of current discharge processes, 17 days of semi-structured observations of the ICU discharge process was undertaken by one researcher over approximately five months. Participants included 85 staff: 68 from ICU (52 nurses and 16 doctors), 15 from the wards (13 nurses and 2 doctors) and 2 other staff members. Fifty-six interviews with 46 ICU and ward staff were conducted to clarify observations (Table 1). These interviews were audio-taped and later transcribed. Some observations focused on ICU nurses' and doctors' activities and communication with ward staff, both in person and via the telephone, while other observations of ward staff activities and communication were based in the receiving wards. Observations began prior to the morning handover at about 0700 and continued throughout the day, until approximately 2200. Policy documents and discharge documentation were also examined.

Table 1: Health Professional Sample

\begin{tabular}{lccc}
\hline Professional Group & ICU & Wards & Total \\
& $\mathrm{n}=68(80 \%)$ & $\mathrm{n}=17(20 \%)$ & $\mathrm{n}=85(100 \%)$ \\
\hline Nurses & $52(62 \%)$ & $13(15 \%)$ & $65(76 \%)$ \\
Doctors & $16(19 \%)$ & $2(2 \%)$ & $18(21 \%)$
\end{tabular}


Process mapping and content analysis were used to analyse the observational and interview data. This process mapping entailed schematically documenting the steps in a process, which helps to identify complexities, overlaps and gaps. The content analysis was an iterative process of reading and rereading transcripts, with members of the research team examining the interview data in a recursive manner, searching for similarities and differences both within and across transcripts. Similar ideas were then organised into categories, and linked to the steps in the process.

Analysis showed that a four-step process was routinely used for discharges. First, projected patient discharges were routinely discussed during morning rounds. Second, for planned discharges, ICU nurses prepared patients by gradually decreasing their monitoring and discussing the discharge with them and their families, using an ICU discharge planning booklet. This booklet focused on what patients and families could expect once the patient was discharged to the ward, such as lower nurse to patient ratios and typical ward routines. Third, the ICU Charge Nurse notified the hospital's bed manager of planned discharges. Fourth, on the day of discharge, telephone notification was provided to the receiving ward as soon as a ward bed became available, followed by a comprehensive handover. ICU nurses generally accompanied patients to the ward and provided a brief face-to-face handover to ward staff.

Three major problems related to the discharge process were identified. The first was a lack of effective discharge coordination, with ward staff lacking awareness of the imminent discharge. This was linked to the second problem, which revolved around interruptions in the chain of verbal and written communication between ICU 
and ward nurses. ICU nurses gave extensive telephone handovers prior to patient discharges, but this verbal report was provided to Charge Nurses on the wards, whose main focus was on bed and staff allocation. They did not record or share a lot of this information with the ward nurse who was assigned to care for the patient. A further disruption in communication often occurred when ICU nurses physically delivered the patient to the ward. If the relevant ward nurse was not available, face-to-face handover did not occur. The central problem was that information transfer occurred at the point of coordination rather than the point of care, with Charge Nurses given too much information, and the nurses who were to care for the patients not receiving enough.

\section{$\underline{\text { Redesigning the ICU Nursing Discharge }}$}

A plan for process redesign was developed to improve the ICU nursing discharge process. The first element of redesign included appointing a change agent, a well-known and respected nursing leader who currently followed up patients discharged from ICU, to facilitate process improvement collaboratively among the wards and the ICU. Second, a patient handover sheet was designed by the ward Charge Nurses and their staff to capture the information required by both groups. The information included patient demographic data, recent observations, diet, mobility, medication, devices, intravenous fluids, oxygen requirements and wound management. The handover sheet was then used to guide the phone handover, and as documentation for the ward Charge Nurses to record information and provide a basis for future reference by ward staff. The information sheet was also used for face-toface handover to the ward nurse who would take over care of the patient. A third important element was notification by ward staff of a specific time they could receive the patient, which allowed ICU nurses to both better plan patient transfers and 
coordinate new ICU admissions. Finally, a daily 'ICU Discharge Alert Sheet' summarising all likely patient discharges was provided to the wards, which allowed the wards to forward plan their staffing and other resources requirements. This alert sheet included explicitly identifying the expected date of discharge to better inform the bedside nurses. The change agent was responsible for educating staff about the new process, developing a poster and bedside summary of the new process to act as memory aids and ongoing support to facilitate face-to-face handovers. That is, once the implementation phase was completed, there was still ongoing support for ICU and ward staff to help to embed the new process into practice. In addition to the change agent facilitating the new process, nursing leaders from both the ICU and ward regularly endorsed the process, however no data were collected on actual compliance to the process.

\section{$\underline{\text { Outcomes }}$}

As the aim of this quality improvement study was process improvement, the primary outcome measure was hours of discharge delay per patient discharged alive per month. Patients were deemed ready for discharge after discharge paperwork, including discharge summary and orders and associated nursing care were completed. Patients were considered to have no delay if this time period was less than one hour (Chaboyer et al. 2006). Secondary outcomes included in-hospital mortality after discharge from ICU and ICU readmission within 72 hours. These outcomes were chosen because several previous studies have shown that other discharge practices can lead to these negative outcomes (Goldfrad \& Rowan 2000; Beck et al. 2002; Duke et al. 2005; Priestap \& Martin 2006; Bell \& Sales 2004; Laupland 2008). All outcome data were accessed from the routinely collected Australia and New Zealand Intensive Care Society Centre for Outcome and Resource Evaluation (CORE) database for 15 
months prior to (January, 2007 to March, 2008) and 12 months after (May, 2008 to April, 2009) the new discharge process was implemented, which began in April, 2008. This database, or registry, captures a large amount of data about patients who are admitted to ICUs in Australia. Demographic and clinical data as well as some patient outcomes such as mortality and ICU readmission are recorded in CORE. An experienced and trained data manager was employed full time to collect and enter data into CORE. The database has built-in quality checks and manual checks of the data quality are conducted on a monthly basis. Data from the CORE database were transferred electronically to the SPSS database.

\section{$\underline{\text { Data Analysis }}$}

Statistical process control (SPC) charts (Benneyan et al. 2003; Speroff \& O'Conner 2004) were used to analyse the variation in outcome data related to the number of patients discharged alive within each respective month, both prior to and after implementation of the new ICU discharge process. SPC charts are graphs that plot the outcome of interest on the y-axis and time on the x-axis. Next, the mean value of the outcome is calculated and is represented as a dotted 'middle line' in the graph, with either 1, 2 or 3 standard deviations, termed control limits (CL) represented as hatched lines both above and below the middle line. Process change is assumed to occur if one of the following conditions occurs: 2 out of 3 successive points are greater than 2 standard deviations from the mean on the same side of the mean; 8 successive points occurring on the same side of the mean; or 6 successive points increasing or decreasing on visual inspection (Benneyan et al. 2003). Similar to the way the level of measurement influences the statistical test that can be undertaken with the data, SPC analysis also has specific tests for specific kinds of data, such as continuous or categorical. 
We employed three types of SPC charts: XmR, P and U. The XmR charts were used to graph the variation of the average monthly discharge delay (i.e. hours of discharge delay/number of patients discharged alive per month). The XmR charts were chosen for this set of data because the outcome (average monthly discharge delay) was a continuous variable, available only as a single data point in each month (i.e. no subgroups) (Benneyan et al. 2003; Mohammed et al. 2008). XmR charts consist of two charts; the $\mathrm{X}$ chart is a control chart of the $n$ observed values and the $\mathrm{mR}$ chart of the moving ranges (Mohammed et al. 2008). The P-chart was used to plot the proportions of the monthly hospitality mortality to the number of patients discharged alive, because mortality data is binary (dead/alive). Finally, since the frequency of monthly patient readmission within the first 72 hours after discharge is categorical, U-chart was appropriate to graph the ratio of this particular set of data to the total number of patients discharged to the wards per month.

For each type of the SPC charts above, we undertook two analyses. The first examined the dataset as a whole for the duration of the data collection period. This first analysis established an overall mean values of the variable data points (displayed as a dotted line) and 2 standard deviations from the mean, also termed the $95 \%$ control limits (displayed as two hatched lines on either side of the mean line). The second analysis involved splitting the same data into two sets, pre and post implementation, with a mean value calculated separately for each set of the data. Preand post-intervention mean values are reported in text, accompanying each SPC chart to assist in interpretation.

\section{$\underline{\text { Results }}$}

A total of 1,787ICU discharges were included in this study, 1,001 in the 15 months before and 786 in the 12 months after the implementation of the redesigned 
nursing discharge processes. Bed occupancy in the main wards ICU patients were discharged to prior to the redesign ranged from $84-95 \%$ and from $84-100 \%$ after. Table 2 displays characteristics of patients discharged from the ICU, before and after implementation of the new discharge process. While the two groups were similar on most characteristics, including their severity of illness, as identified by the Acute Physiological and Chronic Health Evaluation (APACHE) scores and the Simplified Acute Physiology Score (SAPS), more patients in the redesigned discharge process group were admitted electively.

Table 2: Patient Characteristics 15 Months Prior and 12 Months after the ICU Nursing Discharge Process Redesign

Characteristic Prior to ICU Nursing After ICU Nursing Discharge

Discharge Process Redesign

$$
\mathrm{n}=1,001
$$

Median (IQR)

\begin{tabular}{lcc}
\hline Age & $56.0(33)$ & $56.0(30)$ \\
APACHE 2 Score & $12.0(8)$ & $12.0(8)$ \\
APACHE 3 Score & $40.0(30)$ & $40.0(29)$ \\
SAPS & $24.0(19)$ & $22.0(18)$ \\
ICU LOS (hours) & $32.0(56)$ & $25.0(39)$ \\
Hospital LOS (hours) & $259.0(311)$ & $245.0(347)$ \\
\hline & Frequency (\%) & Frequency (\%) \\
\hline Male & $606(60.5)$ & $287(36.6)$ \\
$*$ Elective ICU Admission & $285(28.5)$ &
\end{tabular}

APACHE acute physiological and chronic health evaluation, SAPS , ICU intensive care unit, LOS length of stay 
$* \mathrm{p}<0.05$

Figure 1 shows the average hours of discharge delay per patient per month during the study period, indicating process improvement after implementation (i.e. 8 successive points below the mean line after the intervention). Overall, patients had an average delay time of 3.2 hours (4.6 prior and 1.0 after the intervention). This reduction in delay time corroborated the process improvement identified from the $\mathrm{XmR}$ charts.
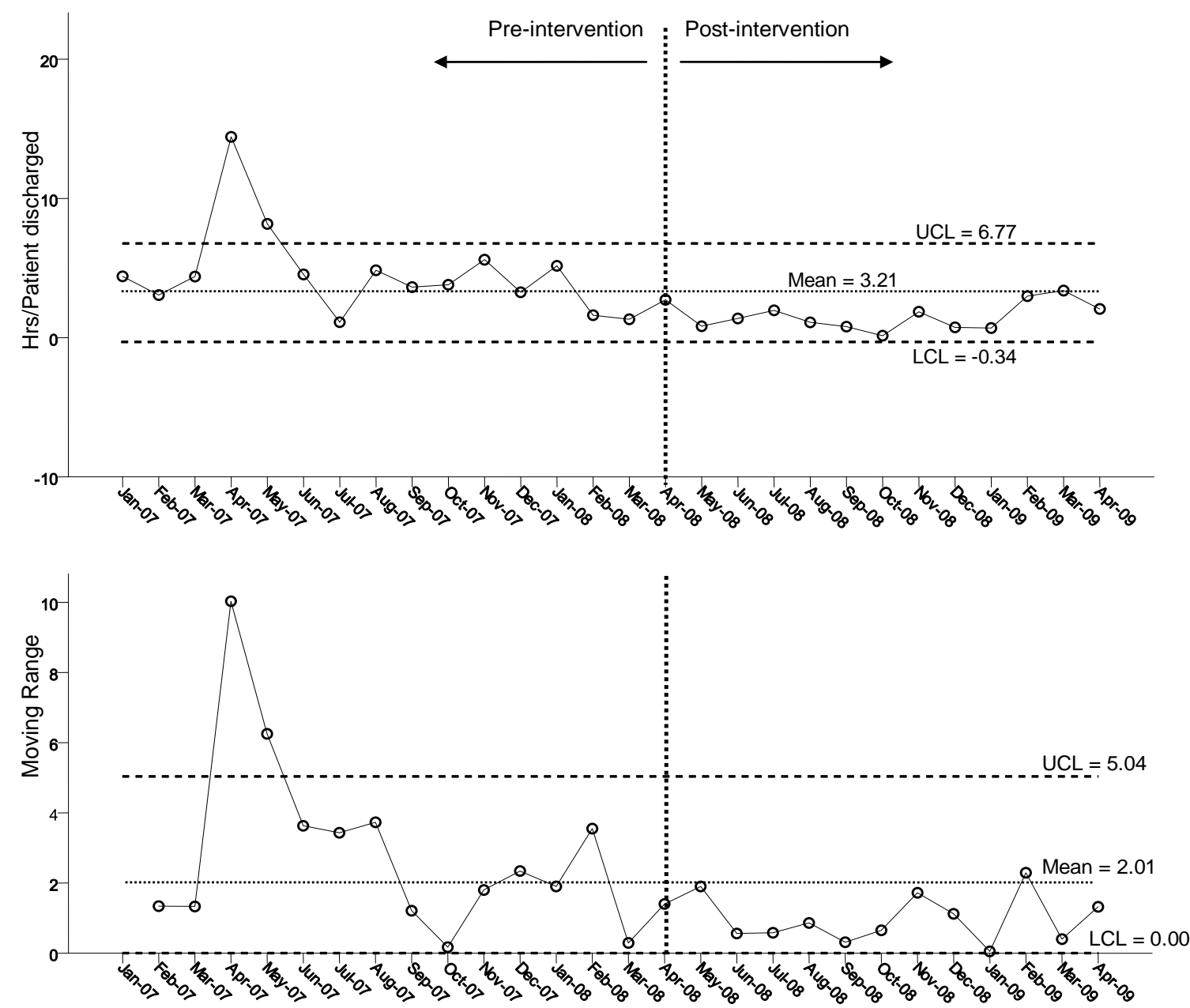

Figure 1: XmR Charts; Average Monthly Discharge Delay (Hours/Patient discharged) 
Figure 2 displays patient mortality in the wards after discharge from ICU. This graph indicates that overall, $4 \%$ of patients died in hospital after ICU discharge. No process change over time is indicated.

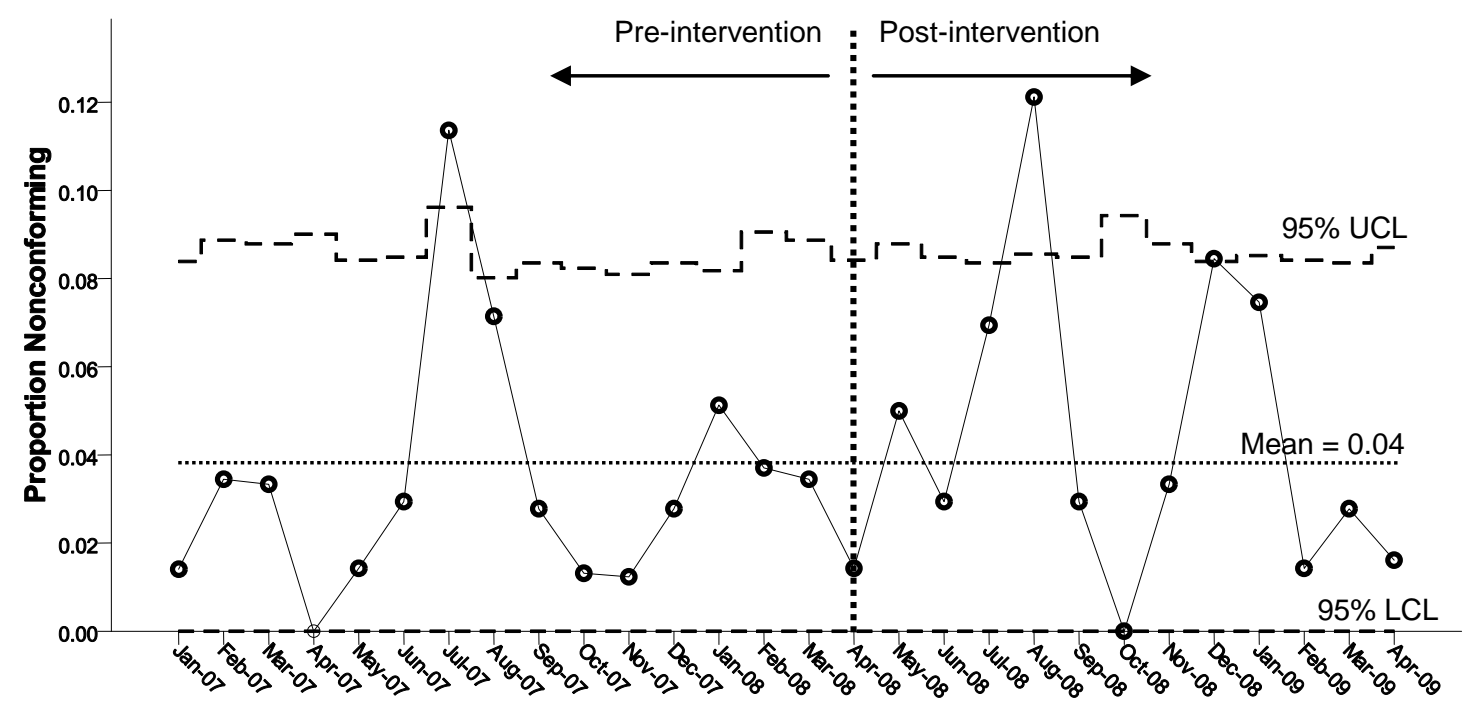

Figure 2: P-Chart; Hospital Mortality of Patients Discharged Alive to the Ward

Figure 3 shows that overall, $2 \%$ of patients experienced a readmission within 72 hrs. It too indicates no process change over time.

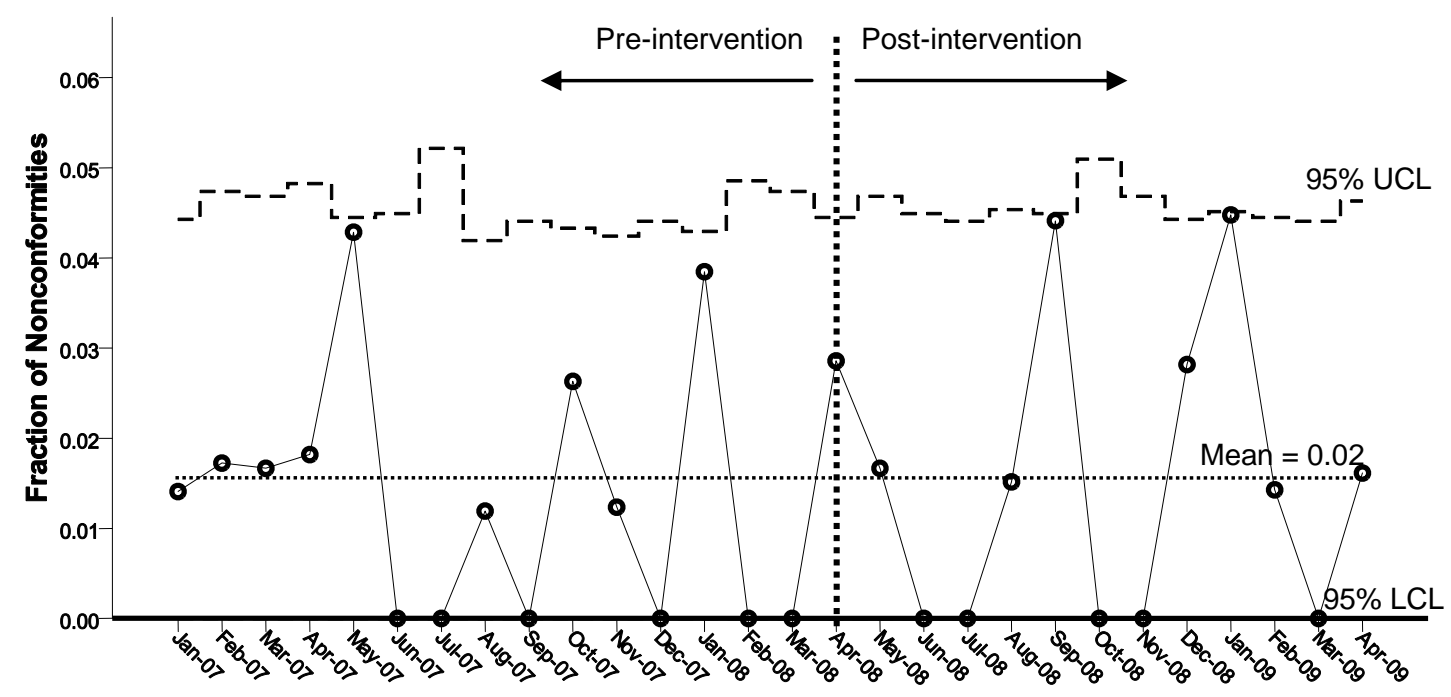

Figure 3: U-Chart; Proportion of ICU Readmission within 72 hours

\section{$\underline{\text { Discussion }}$}


Using a time serries design and SPC analysis, this study showed that redesigning the ICU nursing discharge process decreased ICU discharge delay, without increasing mortality or ICU readmission rates. A number of key principles underpinned this redesign. While recent research has examined the process from the ICU to the ward (Perrens et al. 2008; Shahani et al. 2008), our observational data of ward nursing practices was able to highlight inefficient and ineffective ward routines that had influenced the ICU discharge process. The fact that information provided in the telephone handover did not reach the nurses who required it highlighted a potential risk to patient safety. The importance of the right information being given and understood by the right people at the right time is key to ensure patient safety during the handover process (Australian Commission on Safety and Quality in Health Care 2009).

Planning for change was collaborative, with a change agent leading the overall process improvement phase, and ward staff identifying the information they required for redesign of the handover sheet. This meant that the 'end users' of the information had input into what information was shared and may have improved information flow and knowledge transfer. We propose that the redesign may have enhanced knowledge transfer (i.e. better use of information) (Davenport \& Prusa 1998), rather than simple information sharing, which may have resulted in a better ability to plan to receive discharged ICU patients, ultimately shortening the length of time required to accept the patient.

Redesigning the process also ensured that written handover notes were available to those who were not part of the verbal handover. These notes supplemented the formal documentation in patients' medical records, and were intended as a quick reference during the initial handover of patient information. This 
system of recording handover notes has implications for enhancing the accuracy of information, particularly in light of previous research having shown that over a quarter of medical ICU discharge documentation contained inaccuracies (Perrens et al. 2008). The nursing handover sheet formalised the handover process, underlining its importance. It also specified a minimum data set to be handed over, which may have helped to streamline the handover, thereby improving its efficiency. It is likely that the handover sheet developed in this project acted as a cognitive aid to decisionmaking, which, as using checklists in other aspects of critical care, has been found to promote quality of care (Pronovost et al. 2003; Hewson \& Burrell 2006; Bynes et al. 2009).

Both the discharge alert sheet and documenting the expected date of discharge were strategies to help inform nursing staff of daily plans. Such information allowed various groups of nurses to better plan their work. Identifying the "expected discharge date" can provide the medical and nursing staff the opportunity to prepare patients' discharge in a planned and timely manner. This may prevent the rush on the day of discharge, with the junior doctors trying to complete all the paperwork and nursing staff trying to go through the discharge checklist under time pressures. The fact that, in her official role of following up patients discharged to the ward, the change champion had ongoing contact with both ICU and ward staff, may have helped embed the new processes into practice. The use of change champions, facilitators or educators, to promote ongoing adherence to new practices has been identified in both the theoretical and empirical literature. For example, the Promoting Action on Research Implementation in Health Services (PARIHS), (Rycroft-Malone et al. 2002) and the Outcomes-focused knowledge translation framework (Doran \& Sidani, 2007) both identify facilitation as key components of promoting the use of research in 
practice. Examples of recent research that has used some form of change champion include a description of implementing medication safety guidelines (Bucknall, 2007) and improving handover communication (Stead et al., 2009). There are also a number of other strategies that can be used to embed and sustain practice change. For example, Simpson and Doig (2007) used several strategies in combination to implement new guidelines for nutrition support for intensive care patients, including educational outreach, academic detailing, opinion leaders, audit and feedback, reminders, and in-services. In fact, several systematic reviews even describe the relative effects of various strategies to implement change in clinical practice (see for example, Cheater et al., 2005; Davis \& Taylor-Vaisey, 1997; Grimshaw et al., 2001). The entire redesign process also enhanced teamwork, engaging ward staff, and promoting shared understanding and joint ownership among ICU and ward nurses of the problems and possible solutions associated with ICU discharge. This resonates with the concept of shared situational awareness; being aware and understanding information relevant to the current environment and task, and the foundation for decision-making (Wright \& Endsley 2008). Situational awareness helps develop a shared anticipation of what will likely happen in the near future (Wright \& Endsley 2008). Based on shared understanding, efficiencies and effectiveness in the discharge process are more likely.

\section{$\underline{\text { Limitations }}$}

A number of study limitations are acknowledged. First, it took place in one ICU, therefore the results may not be generalisable. However, the site is typical of many Australian ICUs in terms of staffing, skill mix and patient characteristics. Further, the process followed in this study could be replicated in other settings, which would allow nursing discharge improvements to be tailored to the individual setting. 
Second, this study was undertaken as a quality improvement activity and did not measure or control for other potential confounders such as a change in medical or nursing practices, that may have influenced the findings, although bed occupancy, appeared relatively stable throughout the study. Further, to our knowledge there had been no changes in the way medical or nursing services associated with ICU admission and discharge were delivered, nor did the hours of nursing care per patient day on the wards vary. However, unexpectedly, there were fewer emergency admissions after the ICU nursing discharge process was redesigned, which is a possible explanation for the improvement in ICU discharge delay. Yet, the two groups were similar in relation to APACHE scores, ICU and hospital length of stay and both hospital mortality and ICU readmission. Third, we did not study the appropriateness of patient discharges nor patient outcomes. Finally, the improvement is an example of a complex, bundled health service intervention (Conn et al. 2001), where four related improvements were undertaken simultaneously, and as a result, we are unable to identify the relative contribution any one strategy made to the process improvement. It is always possible that one or more of the strategies may not be required to see improvement. Associated with this, we did not measure actual adherence to the redesigned process, however the change agent and nursing leaders from both the ICU and the wards promoted its use. It is possible that the change agent, and not the redesigned process itself was the cause of the improvement in discharge delay.

In conclusion, this quality improvement study using a time series design showed that redesigning the nursing discharge process was associated with less discharge delay in one Australian ICU. The methodology used, which involved first understanding the process from the perspectives of both ICU and ward staff and then involving both groups in the development of a new nursing discharge process, was 
paramount to the process and may have led to enhanced shared situational awareness. However, due to several limitations of the study, further rigorous research is required to more clearly demonstrate the effect of ICU discharge process improvements on various outcomes. 


\section{Acknowledgement:}

Funding for the Baseline Discharge Processes phase of this study was received from the Clinical Practice Improvement Centre, Queensland Health

\section{Author Contribution:}

W Chaboyer was led the conceputalisation of the study and led the data collection, analysis and writing of the manuscript

F Lin contributed to the conceptualisation of the study, collected data for Phase 1 and contributed to writing the manscript.

M Foster contributed to the conceptualisation of the study, assisted with data collection for Phase 1 and 2, collected the data for Phase 3 of the study, and contributed to writing the manscript.

L Retallick collected the data for Phase 2 of the study, and contributed to writing the manscript.

B Richards contributed to the conceptualisation of the study, assisted with data interpretation and contributed to writing the manscript.

K Panuwatwanich contributed to the conceptualisation of the study, led the data analysis and contributed to writing the manscript 


\section{References}

Australian Commission on Safety and Quality in Health Care. (2009). Ossie Guide to Clinical Handover. Sydney: Author.

Australian Medical Association. (2006). Safe handover: Safe patients; guidelines on clinical handover for clinicians and managers. Retrieved 10th March 2009, from http://www.ama.com.au/web.nsf/doc/WEEN-6XFDKN/pdf

Beck, D. H., McQuillan, P., \& Smith, G. B. (2002). Waiting for the break of dawn? The effects of discharge time, discharge TISS scores and discharge facility on hospital mortality after intensive care. Intensive Care Medicine, 28, 12871293.

Bell, C. M., \& Sales, D. C. (2004). Variations in intensive care outcomes by day of week: no weak-end. Intensive Care Medicine, 30(5), 739-741.

Benneyan, J. C., Lloyd, R. C., \& Plsek, P. E. (2003). Statistical process control as a tool for research and healthcare improvement. Quality and Safety in Health Care, 12, 458-464.

Bucknall, T. K. (2007). Implementing guidelines to improve medication safety for hospitalised patients: Experiences from Western Health, Australia. Worldviews on Evidence-Based Nursing, 4(1), 51-53.

Bynes, M. C., Schuerer, D. J., Scallom, M. E., Sona, C. S., Mazuski, J. E., Thomas, J. M., et al. (2009). Implementation of a mandatory checklist of protocols and objectives improves compliance with a wide range of evidence-based intensive care unit practices. Critical Care Medicine, 37(10), 1-7.

Chaboyer, W., Foster, M., Kendall, E., \& James, H. (2004). The impact of a liaison nurse on ICU nurses' perceptions of discharge planning. Australian Critical Care, 17(1), 25-32. 
Chaboyer, W., Thalib, L., Foster, M., Elliott, D., Endacott, R., \& Richards, B. (2006). The impact of an ICU liaison nurse on discharge delay in patients after prolonged ICU stay. Anaesthesia and Intensive Care, 34(1), 55-60.

Cheater, F., Baker, R., Gillies, C., Hearnshaw, H., Flottorp, S., Robertson,N., Shaw, E. J. \& Oxman, D. (2005). Tailored interventions to overcome identified barriers to change: effects on professional practice and health care outcomes. Cochrane Database of Systematic Reviews, Issue 3 Art. No.: CD005470. DOI: $10.1002 / 14641858 . C D 005470$.

Conn, V. S., Rantz, M. J., Deidre, D., Wipke-Tevis, D. D., \& Maas, M. L. (2001). Designing effective nursing interventions. Research in Nursing and Health, $24,433-442$.

Crocker, C., \& Keller, R. (2005). Nurse-led discharge to the ward from high dependency: a service improvement project. Intensive and Critical Care Nursing, 21, 363-366.

Davenport, T., \& Prusa, L. (1998). Working Knowledge. Cambridge Mass: Harvard Business School Press.Davis, D. A. \& Taylor-Vaisey, A. (1997). Translating guidelines into practice. A systematic review of theoretic concepts, practical experience and research evidence in the adoption of clinical practice guidelines. Canadian Medical Association Journal, 1997; 157:408-416.

Doran, D. \& Sidani, S. (2007). Outcomes-focused knowledge translation: A framework for knowledge translation and patient outcomes improvement. Worldviews on Evidence-Based Nursing 2007; 4(1), 3-13.

Duke, G. J., Green, J. V., \& Briedis, J. H. (2005). Night-shift discharge from intensive care can increase the mortality-risk of ICU survivors. Anaesthesia and Intensive Care, 32(5), 697-701. 
Gajic, O., Malinchoc, M., Comfere, T. B., Harris, M. R., Achouiti, A., Yilmaz, M., et al. (2008). The Stability Workload Index for Transfer score predicts unplanned intensive care patient readmission: Initial development and validation. Critical Care Medicine, 36(3), 676-682.

Goldfrad, C., \& Rowan, C. (2000). Consequences of discharges from intensive care at night. Lancet, 355, 1138-1142.

Grimshaw, J. M, Shirran, L., Thomas, R., Mowatt, G., Fraser, C., Bero, L., Grilli, R., Harvey, E., Oxman, A. \&, O'Brien, M. A. (2001). Changing provider behavior: an overview of systematic reviews of interventions. Medical Care, 39(8 Suppl 2), II2-45.

Hall-Smith, J., Ball, C., \& Coakley, J. (1997). Follow-up services and the development of a clinical nurse specialist in intensive care. Intensive and Critical Care Nursing, 13, 243-248.

Heidegger, C. P., Treggiari, M. M., \& Romand, J. A. (2005). A nation-wide survey of intensive care unit discharge practices. Intensive Care Medicine, 31, 16761682.

Hewson, K. M., \& Burrell, A. R. (2006). A pilot study to test the use of a checklist in a tertiary intensive care unit as a method of ensuring quality processes of care. Anaesthesia and Intensive Care, 34, 322-328.

Intensive Care Society. (1997). Standards for intensive care units. from http://www.dh.gov.uk

Laupland, K. B., Shahpori, R., Kirkpatrick, A. W., \& Stelfox, H. T. (2008). Hospital mortality among adults admitted to and discharged from intensive care on weekends and evenings. Journal of Critical Care, 21, 317-324. 
Levin, P. D., \& Sprung, C. L. (2001). The process of intensive care triage. Intensive Care Medicine, 27, 1441-1445.

Levin, P. D., Worner, T. M., Sviri, S., Goodman, S. V., Weiss, Y. G., Einave, S., et al. (2003). Intensive care outflow limitations: Frequency, etiology, and impact. Journal of Critical Care, 18(4), 206-211.

McLaughlin, N., Leslie, G., Williams, T., \& Dobb, G. J. (2007). Examining the occurrence of adverse events within 72 hours of discharge from the ICU. Anaesthesia and Intensive Care, 35, 486-493.

Mohammed, M. A., Worthington, P., \& Woodall, W. H. (2008). Plotting basic control charts: tutorial notes for healthcare practitioners. Quality and Safety in Health Care, 17, 137-145.

Moreno, R., \& Agthe, D. (1999). ICU discharge decision-making: are we able to decrease post-ICU mortality? Intensive Care Medicine, 25, 1035-1036.

Moreno, R., Miranda, D. R., Matos, R., \& Fevereiro, T. (2001). Mortality after discharge from intensive care: the impact of organ system failure and nursing workload use at discharge. Intensive Care Medicine, 27(6), 999-1004.

Perrens, A., Conte, P., De Bitonti, N., Limoni, C., \& Merlani, P. (2008). From the ICU to the ward: cross-checking of the physician's transfer report by intensive care nurses. Intensive Care Medicine, 34, 2054-2061.

Priestap, F. A., \& Martin, C. M. (2006). Impact of intensive care unit discharge time on patient outcomes. Critical Care Medicine, 34(12), 2946-2951.

Pronovost, P. F., Berenholtz, S., Dorman, T., Lipsett, P. A., Simmonds, T., \& Haraden, C. (2003). Improving communication in the ICU using daily goals. Journal of Critical Care, 18(2), 71-75. 
Rycroft-Malone J., Kitson A., Harvey G., McCormack B., Seers K., Titchen A. et al. (2002). Ingredients for change: Revisiting a conceptual framework. Quality and Safety in Health Care, 11, 174-180.

Shahani, A. K., Ridley, S. A., \& Nielsen, M. S. (2008). Modelling patient flows as an aid to decision making for critical care capacities and organisation. Anaesthesia, 63, 1074-1080.

Simpson, F., \& Doig, G. S. (2007). The relative effectiveness of practice change interventions in overcoming common barriers to change: a survey of 14 hospitals with experience implementing evidence-based guidelines. Journal of Evaluation in Clinical Practice, 13(5), 709-15.

Smith, L., Orts, C. M., O'Neil, I., Batchelor, A. M., Gascoigne, A. D., \& Baudouin, S. V. (1999). TISS and mortality after discharge from intensive care. Intensive Care Medicine, 25, 1061-1065.

Society of Critical Care Medicine. (1999). Guidelines for ICU admission, discharge, and triage. Critical Care Medicine, 27(3), 633-638.

Speroff, T., \& O'Conner, G. T. (2004). Study designs for PDSA quality improvement research. Quality Management in Health Care, 13(1), 17-32.

Stead, K, Kuman, S., Schultz, T. J., Tiver, S., Pirone, C., Adams, C. J. \& Wareham, C. A. (2009). Teams communicating through STEPPS. Medical Journal of Australia, 190(11 Suppl), S128 - S 132.

Tobin, A. E., \& Santamaria, J. (2006). After-hours discharges from intensive care are associated with increased mortality. Medical Journal of Australia, 184(7), 334-337.

Whittaker, J., \& Ball, C. (2000). Discharge from intensive care: a view from the ward. Intensive and Critical Care Nursing, 16(3), 135-143. 
Wright, M. C., \& Endsley, M. R. (2008). Building situational awareness in healthcare settings. In C. P. Nemeth (Ed.), Improving Healthcare Team Communication (pp. 97-114). Ashgate; Hampshire, England. 